\title{
Alsophis rijgersmaei (Anguilla Bank Racer). Behavior.
}

Date of observation: 10 October 2013. Location: Grand Colombier, Saint-Barthélemy. Coordinates: 17.921594, -62.867428. Elevation: $65 \mathrm{~m}$. Voucher: image. First observation of nocturnal activity in the normally diurnal genus Alsophis, away from artificial illumination. A large Anguilla Bank Racer, estimated at $130 \mathrm{~cm}$ in total length, was observed moving in the leaf litter at 22:12, 4 hours after sunset and one day before the first quarter moon. The snake did not react to a camera flash or light from a headlamp and continued its movement slowly away from the trail. The eyes of the snake were metallic blue in the glare of the of the headlamp.

Karl Questel, St. Jean, St. Barthelemy, Guadeloupe, 97133, French West Indies, karlquestel@gmail.com.

Citation: Questel K. 2013. Alsophis rijgersmaei (Anguilla Bank Racer). Behavior. Caribbean Herpetology 48:1.

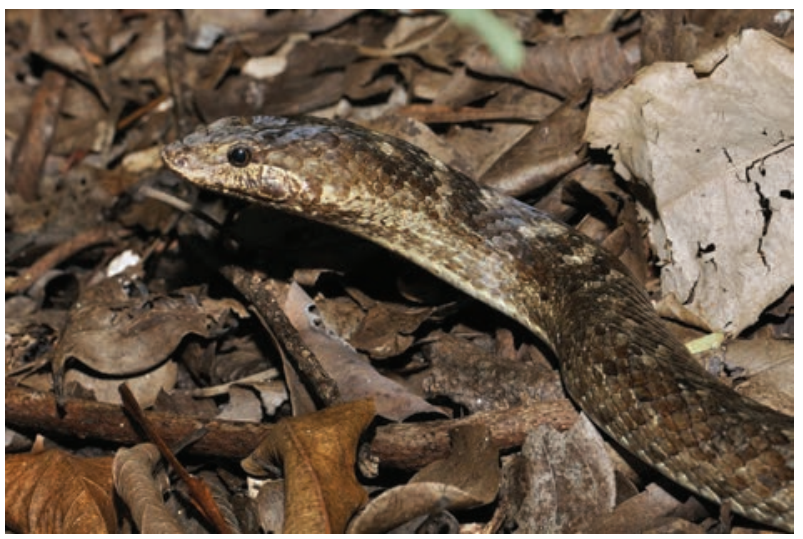

Published online 28 October 2013 